\title{
PLANIFICAÇÃO DE COLMOS DE BAMBU PARA PRODUÇÃO DE PAINÉIS
}

\section{FLATTENING BAMBOO CULMS FOR PANELS PRODUCTION}

\author{
Celso Salamon, Dr. Eng. Mecânica (UTFPR-CT); \\ Fabiano Ostapiv, Dr. Eng. Mecânica (UTFPR-PB).
}

\author{
Palavras Chave \\ Processamento de bambu; equipamento para planificar bambu; painéis compostos de bambu.
}

\section{Key Words}

Bamboo processes; bamboo flattening's machine, bamboo composites panels.

\section{RESUMO}

Neste artigo são analisados aspectos do processamento primário de colmos de bambu por conformação mecânica a frio a partir de um equipamento para abrir estes colmos produzindo superfícies planas. $O$ equipamento protótipo projetado e construído pelo autor foi concebido para testar os conceitos e requisitos do processo proposto. Nos experimentos foram usadas partes de colmos das espécies Phyllostachys áurea, Phyllostachyspubescens e Bambusa tuldoides. A partir dos colmos seccionados e planificados foram produzidos diferentes amostras de modelos de painéis compostos usando os recursos de uma marcenaria convencional. Estes painéis resultaram da prensagem de uma composição das peças de bambu planificado com outros materiais lignocelulósicos não convencionais como a fibra seca de coco. Por fim os resultados obtidos com o protótipo e experimentos são discutidos, indicando a viabilidade técnica do processo estudado. São delineadas então as necessidades e requisitos técnicos de um equipamento industrial que possa planificar colmos de diferentes espécies e dimensões, buscando universalizar as aplicações e otimizar o processo proposto.

\section{ABSTRACT}

In this paper, aspects of the primary processing of bamboo culms by cold mechanical conformation are analyzed from an equipment to open these culms producing flat surfaces. The prototype equipment designed and built by the author was designed to test the concepts and requirements of the proposed process. In the experiments, bamboo species Phyllostachys aurea, Phyllostachyspubescens and Bambusa tuldoides were used. From the sectioned and planed culms different samples of composite panel models were produced using the resources of a conventional joinery. These panels resulted from the pressing of a composition of the flatned bamboo culms with other non-conventional lignocellulosic materials such as dry coconut fiber. Finally the results obtained with the prototype and experiments are discussed, indicating the technical feasibility of the process studied. The needs and technical requirements of an industrial equipment are then delineated to processing of different species and dimensions, seeking to universalize the applications and optimize the proposed process 


\section{INTRODUÇÃO}

O bambu é uma planta que pode ser utilizada na sua forma natural ou processada, tendo um amplo leque de usos em áreas que vão, desde a construção civil, até alimentação humana. Esta matéria prima abundante é base para uma grande quantidade de produtos artesanais e industriais, sendo usado com menor ou maior grau de manufatura em função de sua aplicação final como defende, Xiaobing (2007).

A cada nível de processamento da matéria prima, o design e a qualidade agregam valor aos produtos finais obtidos, Marinho (2007).

Este trabalho propõe uma nova forma de processamento primário dos colmos de bambu, usando um equipamento protótipo que produz colmos planificados. É uma melhoria de processamento que agrega valor e pode possibilitar o surgimento de novos produtos, bem como novos empreendimentos. Além disso, a melhoria no processamento primário dos colmos racionaliza e amplia o aproveitamento do material nos empreendimentos já existentes.

O protótipo experimental, projetado e construído pelo autor, foi concebido para testar conceitos e requisitos de processo, ou seja, a planificação de colmos de bambu de médio porte, por conformação mecânica a frio.

A seguir explanam-se os processos primários mais difundidos que permitem a fabricação de painéis, elementos universais que podem ser usados para a construção de muitos outros produtos finais.

Na sequência são mostrados alguns testes do equipamento em uso numa marcenaria escola convencional de Joinville, no intuito de verificar a potencial aplicabilidade do equipamento. Finaliza o trabalho com uma análise dos resultados obtidos.

\section{REVISÃO BIBLIOGRÁFICA}

\subsection{Processamento de bambu visando a ob- tenção de peças planas e regulares}

Quando o bambu não é usado em sua forma natural ou de forma artesanal, processos industriais com maior ou menor mecanização são necessários, estes visam a transformação dos colmos cilíndricos, ocos e geometricamente irregulares, em unidades regulares tais como: ripas, lâminas, partículas, lascas ou pós, que depois, com adesivos e prensas são transformados em produtos compostos tais como: placas, vigas, colunas e, painéis regulares, entre outros.

Na obtenção de ripas, lâminas e outros elementos regulares, normalmente são usadas técnicas de torneamento, serragem, faqueamento longitudinal, fresamento e conformação mecânica sendo posteriormente, com máquinas comuns ao ramo madeireiro obtidos vários produtos finais.

Conforme Hidalgo, (1974) e Xiabing (2007); para o processamento primário de colmos de bambu normalmente são utilizadas as técnicas a seguir:

- Corte com serra refiladeira dupla (doble paralel saw)

- Fendilhamento longitudinal (spliting)

- Torneamento dos colmos (venneer peeling)

- Achatamento (flattened)

Cada um dos métodos tem aspectos característicos particulares, e fatores como dimensão, espécie, geometria dos colmos, disponibilidade, custo, variabilidade das características mecânicas, idade e até aspectos culturais definem sua aplicabilidade, eficiência e resultados obtidos.

Autores como Stamm (2006) e Salamon (2009), dizem que o processamento primário é o ponto crítico na manufatura de laminados que posteriormente podem virar os produtos de bambu laminado colado (BLC). A produção de ripas a partir de colmos serrados, fresados e plainados tem uma eficiência em torno de $27 \%$ do volume total do colmo, segundo Stamm (2006). No entanto, Salamon (2009), mostrou que a produção de lâminas pelo processo de torneamento de colmos regulares de grande diâmetro, pode facilmente ultrapassar estes $27 \%$ de eficiência volumétrica, chegando quase a $50 \%$.

A obtenção de lâminas delgadas e largas por laminação por torneamento apresenta um menor número de etapas de processo comparado com os processos de obtenção de ripas de bambu serrada, fresada ou plainada. Este processo apresenta restrições devido à irregularidade geométrica, fixação dos colmos, e aspectos que precisam de mais estudos e experimentos específicos objetivando maior repetibilidade e confiabilidade. Apesar de algumas vantagens, este processo primário é pouco difundido ao contrário do corte primário dos colmos por serra dupla que é mais popularizado.

No sentido de aumentar a aplicação de laminação por torneamento, pesquisadores das Filipinas, FRDI (2008), desenvolveram um equipamento compacto para este fim e, no Brasil são realizadas pesquisas para propor soluções às restrições inerentes a esta técnica (Salamon,2009).

Outro processo primário é denominado spliting que nada mais é do que seccionar longitudinalmente os pedaços de colmos de bambu usando ferramentas manuais ou mecanizadas tipo facas para produzir ripas, que depois podem ser novamente seccionadas em lâminas mais finas aptas a serem trançadas ou agrupadas de diversas 
formas e prensadas formando placas, painéis e produtos com formas geométricas diversas.

A geometria das ripas e das lâminas está condicionada à ferramenta e ao direcionamento das fibras dos colmos. O seccionamento longitudinal é um processo primário muito difundido, por ser executado tanto manualmente como por máquinas e dispositivos simples.

Os processamentos primários são a base necessária à obtenção de produtos regulares (standart) de bambu que permitirão a confecção de outros produtos industrializados de maior valor agregado. A figura 1 ilustra de forma genérica as diferentes etapas para obtenção de produtos BLC dando ênfase ao processo primário de corte por serra e fresadora. Porém, para produção de um laminado trançado colado, basta substituir a serra e a fresadora de quatro faces por um laminador "spliting" e um tear, mantendo os demais elementos. Para representar a produção de painéis laminados, a serra e a fresadora seriam substituídos por um torno laminador.
Neste arranjo produtivo, várias etapas não são mostradas em detalhes como a silvicultura, os ensaios e etapas intermediárias por não ser objeto de estudo no momento. No entanto, este arranjo mostra a necessidade de inicialmente se obter produtos regulares ou padronizados de bambu para viabilizar a fabricação de produtos como móveis, painéis sarrafeados e laminados. Neste exemplo, como dito anteriormente, para transformar os colmos em ripas, são usados serra circular dupla e fresadora de quatro faces sendo o rendimento da transformação baixo, pois existem sobras de material entre as ripas no corte por serra e é produzido muito cavaco no fresamento até se obter peças regulares.

Figura 01 - Ciclo produtivo ilustrativo de Arranjos Produtivos Locais de bambu guadua.

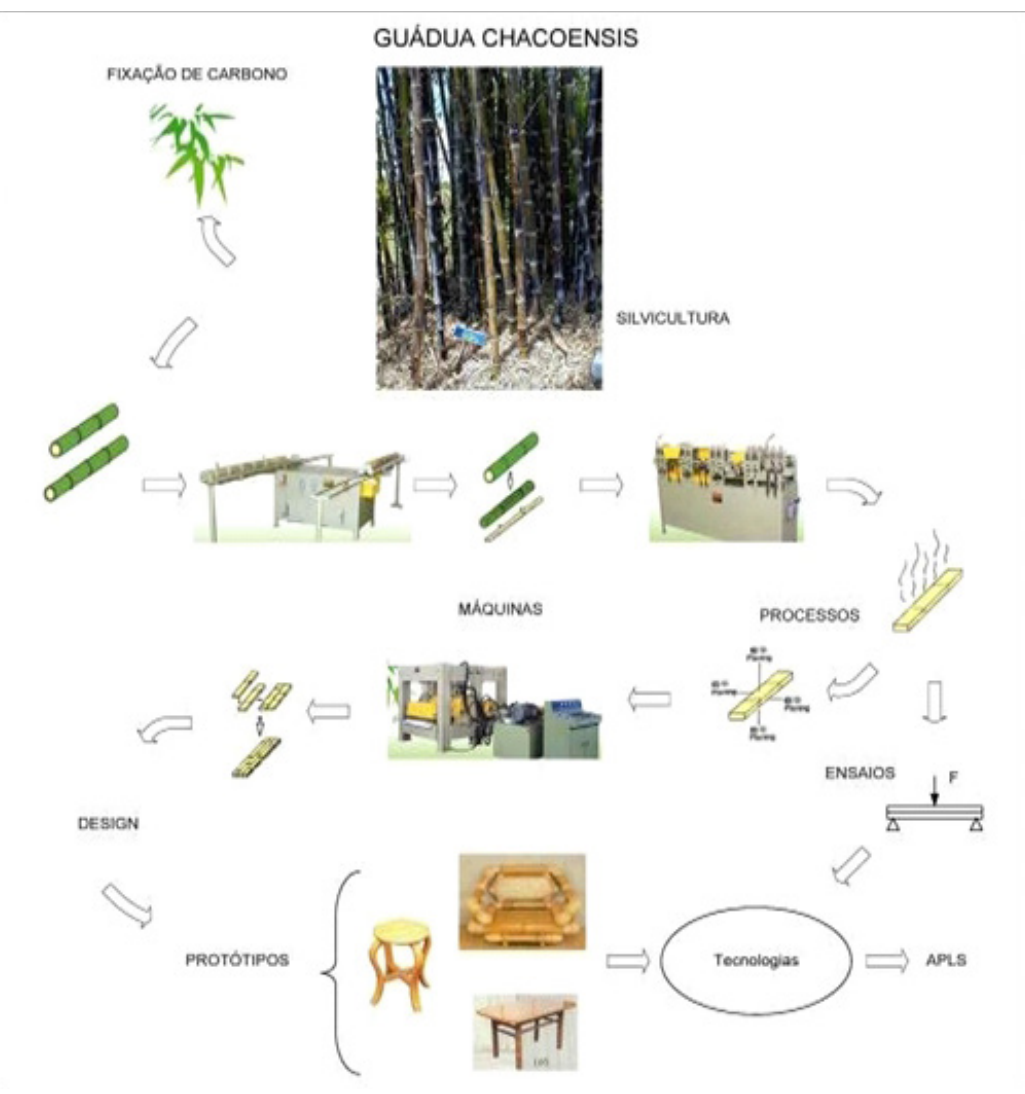




\subsubsection{Processamento tipo "flattened" para pla- nificação dos colmos}

A técnica primária desenvolvida neste projeto para obtenção de uma superfície plana e posteriormente painéis e outros produtos, é baseada no processo por achatamento ou flattened. Razão pela qual este está sendo tratado de forma mais aprofundada.

Como este método, ou boa parte dele, pode ser feito de forma manual ou com baixa mecanização e apresenta alto rendimento volumétrico, é muito popularizado. É comumente usado na Colômbia e em alguns países da Ásia como a Índia, e aos poucos está sendo introduzido no Brasil. No processo manual, um corte longitudinal é feito ao longo de toda a extensão do colmo, como mostra o trabalhador da figura 3. A partir deste corte longitudinal a peça de bambu é aberta com o uso de ferramentas manuais, na sequência de operações mostradas na figura 2 , para obtenção de peças planas.

Figura 02 - Operações para planificação manual dos colmos de bambu
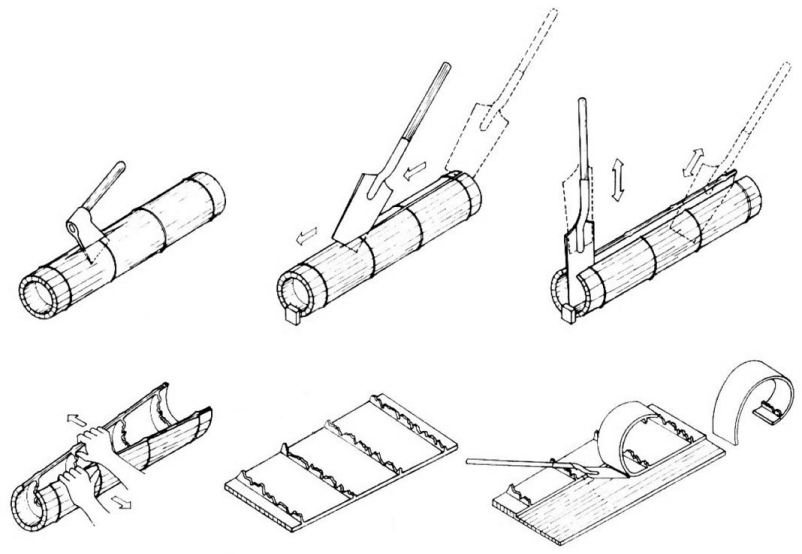

Fonte: GuaduaBamboo.com

É retirada então a parte do material interno do colmo, justamente o material de menor resistência mecânica. A seguir é feita a limpeza da peça que é colocada na vertical para secar ao sol ou em estufas, obtendo assim as peças planificadas com várias rachaduras longitudinais, conhecidas como "esterilas". Depois de secas, as esterilhas podem ser prensadas e coladas em diversos arranjos formando produtos regulares como: vigas, colunas e painéis.

O protótipo desenvolvido e mostrado neste trabalho, mecaniza o processo de planificação de colmos de bambu de médio porte, tendo como referência a produção manual de esterilhas, como mostrado na figura 2 e figura 3.
Figura 03 - Trabalhador abrindo colmo manualmente e esterilhas secando ao natural.

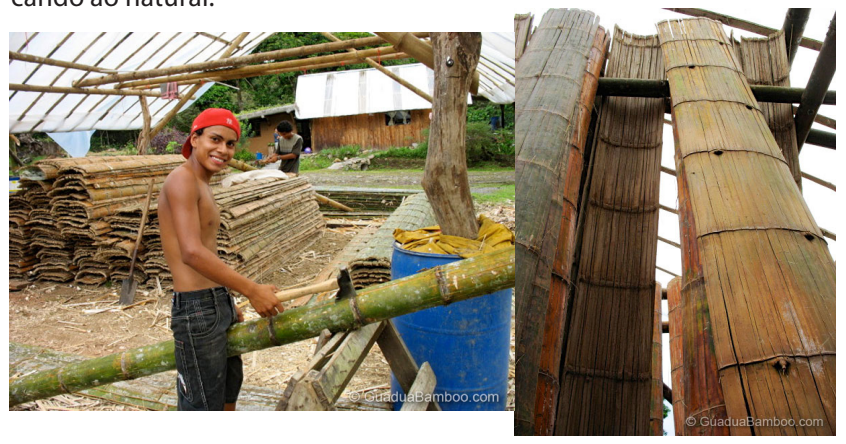

Fonte: GuaduaBamboo.com

Após a obtenção de uma superfície plana de razoável regularidade, produtos como os mostrados nas figuras 4, podem ser fabricados utilizando as técnicas e os equipamentos comuns para processamento de madeira.

Figura 04-Assoalho e tampo de mesa, ambos produzidos a partir de esterilhas.
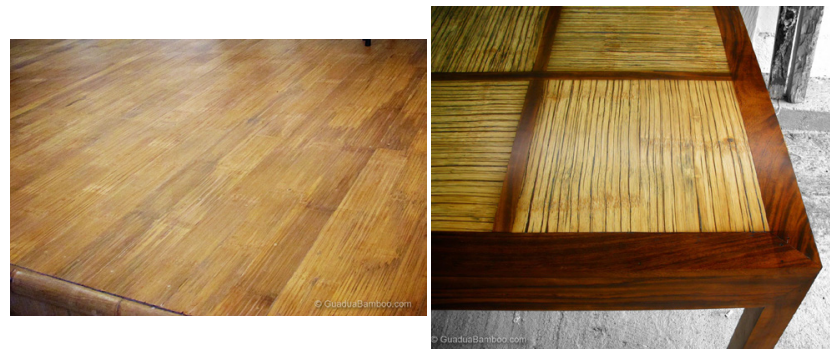

Fonte: GuaduaBamboo.com

O processo de abertura dos colmos em esterilhas, tem se mostrado eficiente na transformação da matéria prima em produto final. Somente a parte interna do colmo é removida, o diafragma e material de baixa resistência mecânica.

Nas próximas etapas, após prensagem, uma pequena parte de material ainda pode ser removida por plainas ou lixadeiras para dar o acabamento final exigido pelo produto. Mesmo assim a quantia de material removido é menor que nos outros processos primários citados.

Por esta característica intrínseca de produção de poucos resíduos, este processo se apresenta como boa alternativa para formação de cadeias produtivas sustentáveis seguindo os conceitos de autores como Leripio et al (2015).

Entre as desvantagens deste processo cita-se a dificuldade de algumas operações, a falta de segurança no manuseio das ferramentas, a repetição exaustiva dos movimentos e a lentidão dos processos manuais envolvidos.

\subsection{Desenvolvimento de estudos para indus- trialização do bambu na UTFPR}

Para cada possibilidade de processamento primário de colmos apresentado anteriormente há necessidade de 
estudos, equipamentos e processos específicos para facilitar e viabilizar empreendimentos de pequeno e grande porte objetivando determinado produto.

Neste sentido, assim como em outras universidades e em algumas iniciativas de outros pesquisadores e empreendedores; têm sido desenvolvidos na UTFPR pesquisas, equipamentos, processos e produtos utilizando esta matéria prima. Entre os estudos e pesquisas cita-se Marinho (2007) que revisou técnicas com baixa mecanização e propôs novas aplicações de bambus em móveis; Ostapiv (2011), que estudou a aplicação em painéis e Oshima (2007), que propôs um equipamento automatizado para serrar bambus.

Os equipamentos até o momento desenvolvidos na UTFPR são experimentais no intuito de entender e resolver problemas específicos para desenvolver as bases de processo para colaborar a viabilização e formação de empresas, cadeias produtivas ou arranjos produtivos locais.

De um modo geral estes projetos de equipamentos têm sido desenvolvidos com alunos em Trabalhos de Conclusão de Curso (TCC) seguindo orientações de projetos de autores consagrados como PAHL et al (2007), e quando possível interagindo e agregando o conhecimento tácito de trabalhadores do ramo da madeira e do próprio bambu, bem como de outros pesquisadores da área.

A figura 5 apresenta um destes equipamentos experimentais desenvolvidos (spliting) e uma amostra de painel laminado trançado produzida a partir deste.

Neste caso os requisitos formulados foram baixo custo, equipamento de baixa complexidade, fácil operação/ manutenção e segurança operacional, sendo obtidos resultados finais satisfatórios. Em momentos subsequentes o equipamento foi emprestado para usuários e melhorias foram implementadas à medida que necessidades específicas foram sendo detectadas. Este equipamento; depois de implementadas as melhorias decorrentes de observações de usuários; está muito próximo de atender o mercado a que foi direcionado: pequenos empreendimentos, associações e artesãos.

Figura 05 - Laminador longitudinal e placa laminada trançada desenvolvidos na UTFPR.
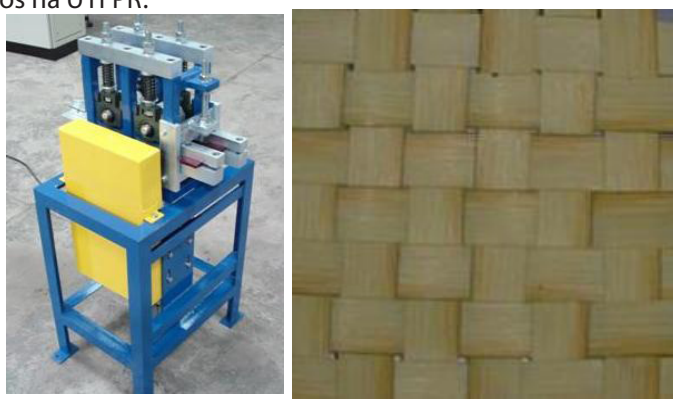

Fonte: Vale e Trinkel, 2007
O projeto ora desenvolvido segue a filosofia dos demais até agora implementados. Sobrepondo o teste de conceitos de planificação, é orientado para pequenos empreendimentos, simplicidade, mobilidade, baixo custo e segurança operacional.

\section{DESENVOLVIMENTO DO EQUIPAMENTO E PROCESSO DE PLANIFICAÇÃO}

A implementação deste projeto requereu o planejamento e execução de fases distintas seguindo orientações de projeto de autores como PAHL et al (2007) e CZIULIK (1998). Na primeira verificaram-se formas de obtenção de superfícies planas e regulares a partir de um colmo conforme apresentado na revisão bibliográfica. $\mathrm{Na}$ sequência foram relacionadas as necessidades do equipamento e processo para planificação de um colmo seguindo o conceito "flattened", sendo então formulados os requisitos do sistema. A partir dos requisitos de projeto foi escolhida a solução que atenderia de forma mais ampla o sistema equipamento/ processo proposto. Após esta etapa foi realizado o projeto aquisição e ou fabricação das partes e construído o equipamento. Os testes e experimentos para se obter amostras de bambu planificado bem como painéis compostos a partir destes, foram realizados em uma marcenaria escola convencional. Para tanto foram agregados aos colmos planificados outras formas de bambu processado e outros materiais. Por fim, são analisados os resultados obtidos pelo equipamento, processos e produtos decorrentes.

A seguir são listadas as necessidades do projeto.

\subsection{Necessidades}

*Equipamento conceito simples e baixo custo, de fácil mobilidade que substitua no todo ou em parte o trabalho manual para planificar um colmo como apresentado na figura 2.

*Reutilização de equipamentos ou partes baseadas na reciclagem industrial

*Testar variadas geometrias e arranjos dos rolos de conformação para compensar a diferença de perímetro interno e externo de um colmo.

*Equipamento ergonômico, operação segura e facilitada. (Mesmo que não plenamente implementados nos experimentos serão previstos e listados os aspectos de segurança que devem ser atendidos quando da transformação do protótipo em produto).

*Baixa potência instalada

* Interagir com profissionais do ramo madeireiro com conhecimento tácito reconhecido. Seja no 
desenvolvimento do equipamento/processo bem como das placas e ou painéis.

*Testar a planificação para colmos de diversas espécies (mínimo três) com pequeno diâmetro e baixa espessura.

*Desenvolver uma placa em uma marcenaria/escola/ pública utilizando espécie de bambu local considerada sem valor econômico e espécie já reconhecida como de alto valor (Mossô- Phyllostachys pubescens).

*Verificar possibilidades de aplicações destas placas nos produtos desenvolvidos na marcenaria escola.

"Velocidade baixa de processamento e ajustável.

\subsection{Requisitos de projeto}

Para atender plenamente as necessidades formuladas, foram definidos três grupos de requisitos de projeto, referentes ao equipamento, matéria prima e processo/ aplicação na fabricação das placas na marcenaria escola.

\subsubsection{Requisitos do equipamento}

* Usar a estrutura de um pequeno laminador de metais fazendo as adaptações necessárias e maximizar a reutilização de componentes, evitando fabricação desnecessária.

* Sinalizar as exigências das normas relacionadas à segurança.

*Aplicar combinação de rolos/discos de conformação/ prensagem com diversas geometrias e acabamento superficial, diâmetro máximo de $100 \mathrm{~mm}$ e ajuste de 1 a 6 $\mathrm{mm}$ entre estes.

* Velocidade de avanço ajustável de 100 a 150 mm/s

* Usar uma fileira de rolos de conformação (Máquina compacta).

\subsubsection{Requisitos da matéria prima}

* Processar bambus das espécies Phyllostachys aurea (Áurea), Bambusa tuldoides (Tuldoide) e Phyllostachys pubescens (Mossô) com idade estimada de 3 a 4 anos, verdes e em variados estados de secagem.

*Diâmetro máximo do colmo de $70 \mathrm{~mm}$ e espessura de parede menor ou igual a $6 \mathrm{~mm}$.

*Colher uma das espécies nas redondezas da marcenaria, para evidenciar a possibilidade de uso de recursos locais para desenvolver novos produtos.

\subsubsection{Requisitos do processo para confecção das placas compostas \\ *Utilizar as instalações da Escola de marcenaria da Prefeitura de Joinville denominada Fundamas Centro XV, cito a Rua Brigada Lopes 153, Bairro Glória, Joinville, Sc. \\ *A partir dos colmos planificados usar somente as}

máquinas, equipamentos e adesivos e técnicas de uso corrente nesta marcenaria.

*Utilizar outros produtos de bambu se necessário (como laminas de bambu, obtidas por torneamento e ripas serradas).

* Usar fibra seca de coco para enchimento e aumento de resistência transversal dos painéis.

\subsection{Projeto e implementação do equipamento e} testes preliminares

Para atender os requisitos formulados foi desenvolvido um projeto conceitual de um planificador/processo usando como base a estrutura de um pequeno laminador de materiais metálicos com potência de $1 \mathrm{cv}$, atendendo o requisito de reciclagem e reuso de materiais e equipamentos.

A figura 6 ilustra o princípio funcional do sistema equipamento/processo proposto. Conforme a figura 6, meio colmo de bambu é forçado a passar uma ou mais vezes entre rolos que devem abrir fendas longitudinais neste, com largura e profundidade determinadas pela geometria e ajuste de distância entre estes rolos, obtendo-se ao final uma superfície plana e com mínimo de rachaduras ou trincas para manter as partes unidas.

Figura 06 - Princípio do planificador e processo. Formação de sulcos e vincos

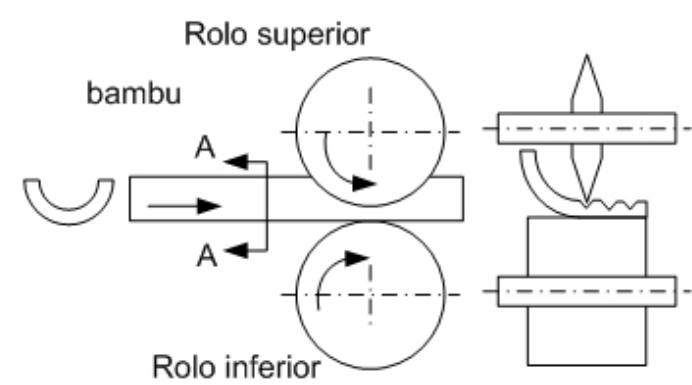

Prensagem Composições diversas
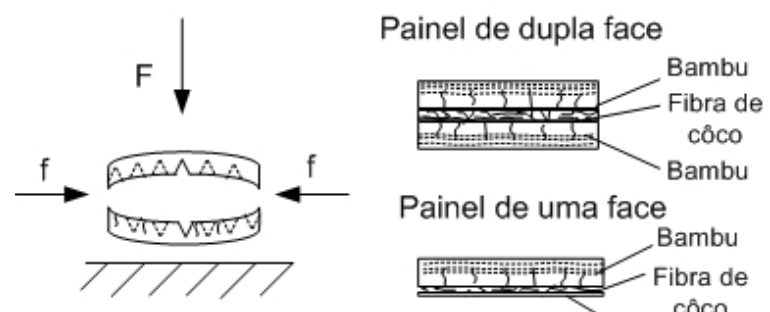

Painel de uma face

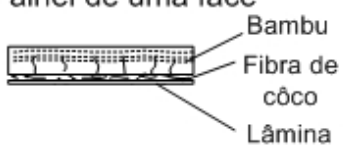

Fonte: Autoria própria

Depois de aberto é efetuada limpeza interna e secagem deste colmo obtendo-se produto similar às esterilhas 
citadas na revisão. Este colmo planificado permitirá se unido a outros materiais e prensado em um ou dois sentidos, formar painéis, placas compostas e outros produtos.

Analisando a figura 7, que representa a seção transversal de um colmo, verifica-se que para se obter uma geometria plana, tem que ser compensada a diferença entre o perímetro interno e externo deste. Para tanto os rolos idealizados, esquematicamente representados na figura 6 , formam sulcos longitudinalmente nas paredes dos colmos. Os sulcos internos maiores e externos menores compensam as diferenças de perímetro interno $(\pi \times \mathrm{Di})$ e perímetro externo ( $\pi \times \mathrm{De})$ do colmo. A dimensão "e" do modelo de colmo planificado apresentado na figura 7 e figura 8 representa a espessura de uma lâmina não conformada e é resultante do ajuste da distância entre os rolos.

Figura 07 - Princípio da planificação

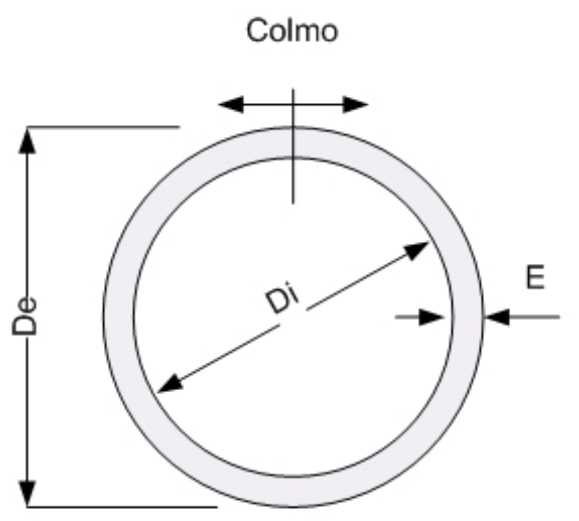

Colmo planificado
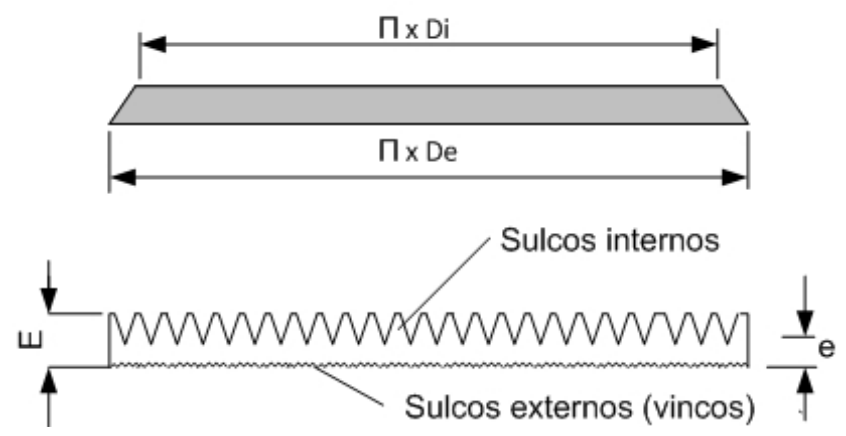

Fonte: Autoria própria

Para facilitar o desenvolvimento do equipamento e processo optou-se pelo corte ao meio dos colmos. A figura 8 representa meio colmo antes e depois de planificado pelo processo.
Figura 08- Meio colmo planificado.

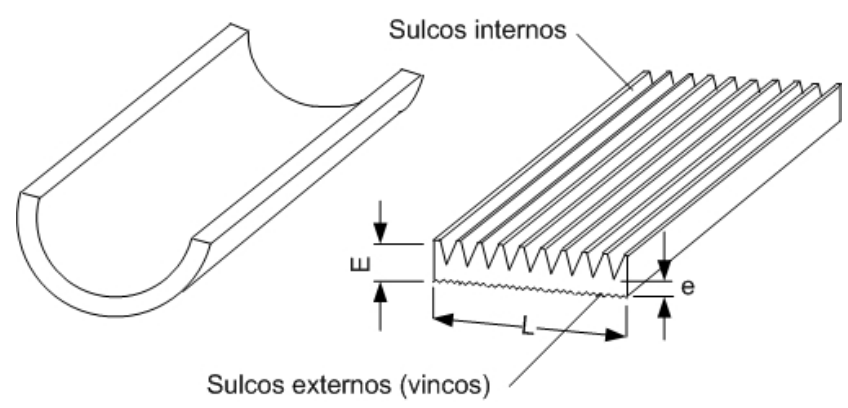

Fonte: Autoria própria

Com os parâmetros definidos foram projetadas, fabricadas e implementadas as alterações no equipamento base (laminador de metais) constituindo o equipamento apresentado na Figura 9.

Figura 09 - Protótipo de equipamento implementado.

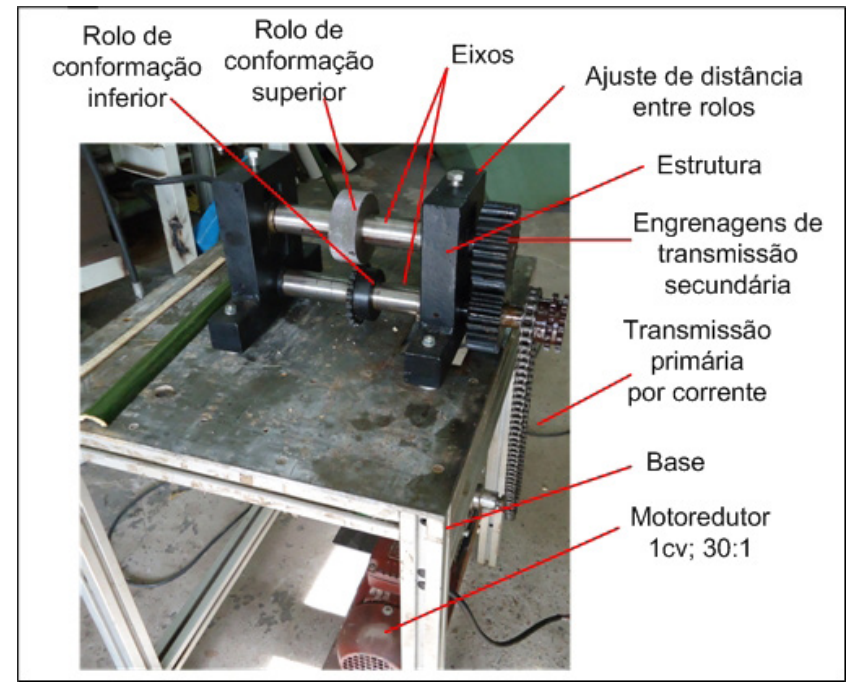

Fonte: Autoria própria

Na sequência, foi realizada uma série de testes com partes de colmos de bambus com e sem nós no sentido de aprender e aprimorar o equipamento e processo, sendo a seguir desenvolvidos os protótipos de painéis na marcenaria apresentada em vista parcial na figura 10. Esta conta com os recursos convencionais para processamento de madeiras, tais como, serra esquadrejadeira, plaina desengrossadeira, serra fita, serra circular, prensa mecânica, lixadeira de cinta e de disco, bancadas e acessórios usuais na área. 
Figura 10 - Vista parcial da marcenaria e painel de bambu sendo processado

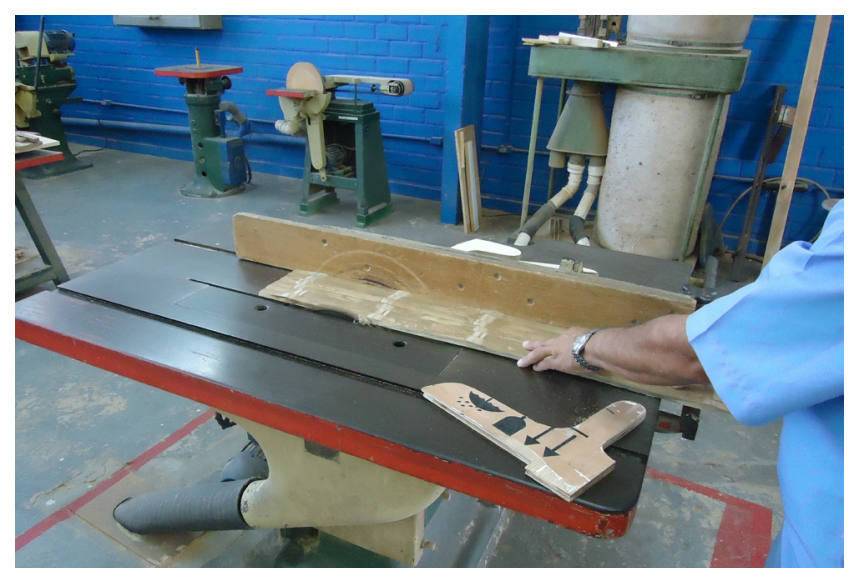

Fonte: Autoria própria

\section{APLICAÇÕES E RESULTADOS}

A seguir são apresentados e discutidos aspectos relevantes resultantes dos experimentos.

O equipamento e processo de planificação propostos atendeu de maneira satisfatória o teste de conceito. Seu uso mostrou-se eficiente no sentido de abrir um colmo de médio diâmetro de forma mecanizada, com facilidade, esforço mínimo e obtendo uma peça de razoável planicidade. Substituindo assim parte do processo manual ora em uso minimizando o esforço laboral. Como esperado, com este projeto adquiriu-se das observações, operação do equipamento, discussões e experiências realizadas um rol de conhecimentos e diretrizes para desenvolver equipamentos mais elaborados que oportunizem alternativa eficiente para a produção de painéis compostos de bambu.

O equipamento planificador proposto, para se tornar produto que atenda amplo leque de necessidades e legislação, deve ser reprojetado e construído com uma série de inovações como limitação de sobrecargas, dispositivos de proteção e segurança para atender plenamente o processo e normas de segurança. No projeto foram previstos e formulados requisitos de segurança, porém estes não foram implementados em sua totalidade por se tratar de teste de conceitos e que estes seriam realizados em situação de pleno controle.

Foram desenvolvidas diferentes geometrias e combinações dos rolos e discos de conformação para maximizar a planificação e minimizar o rompimento das paredes. A figura 11 apresenta duas das combinações de rolos entre várias testadas. Nesta figura, na parte de cima o rolo superior (responsável pelo vinco externo) esta combinado com um rolo ou disco inferior com uma única aresta e dentes para criar sulcos profundos nos colmos de maior espessura ou ainda para pré abertura destes, bem como melhorar o tracionamento. Nesta figura 11, na parte de baixo, o rolo superior foi deslocado para combinar com um rolo inferior com varias arestas. Através de uma ou várias passagens do colmo previamente cortado ao meio pela combinação destes rolos ajustados a certa distancia entre eles, foram obtidos sulcos longitudinais com perfil e profundidade específicas obtendo-se uma peça plana, ou com razoável planicidade. A figura 12 apresenta três tipos distintos de sulcos decorrentes dos rolos e ajustes destes.

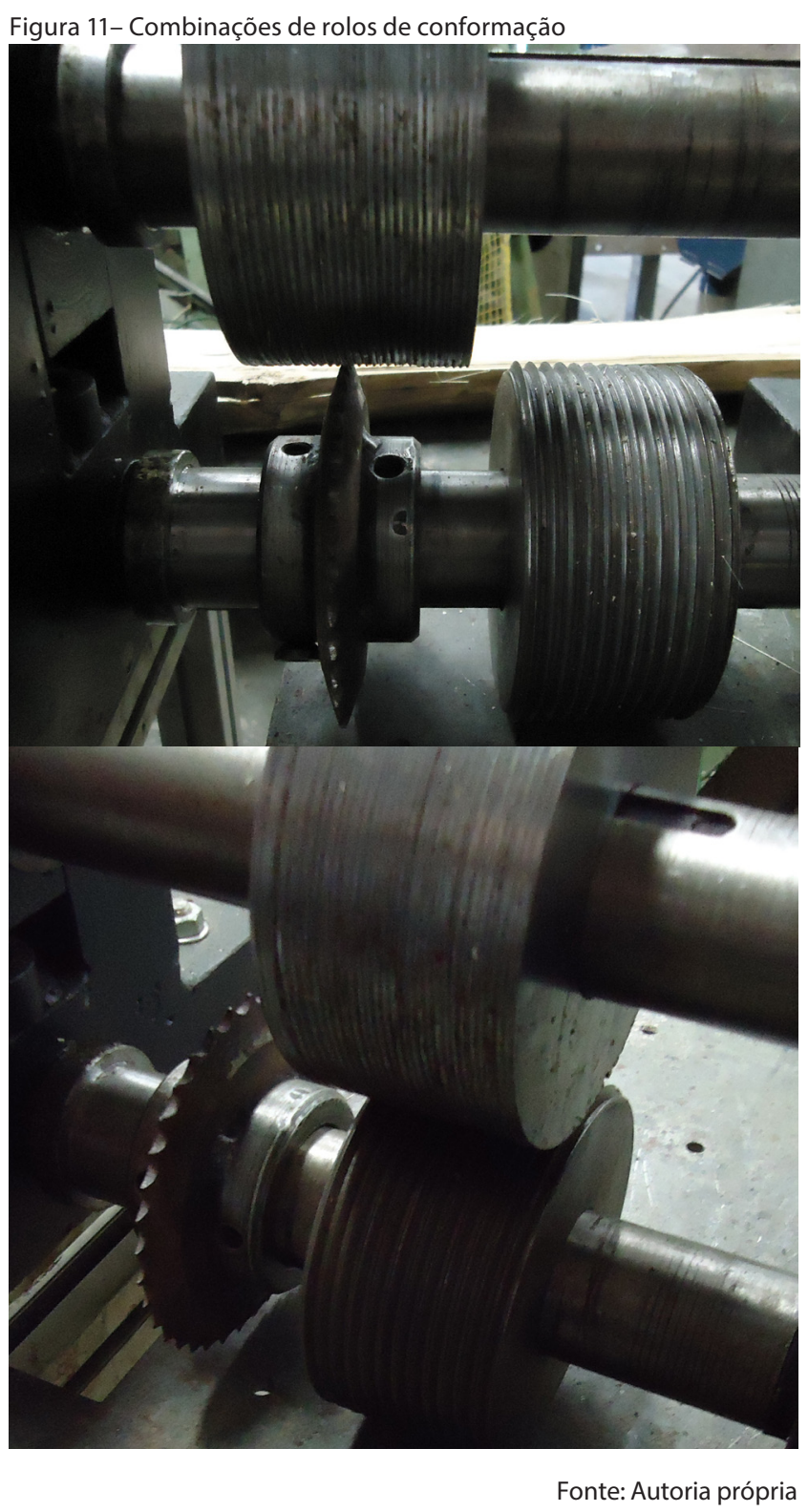

A opção de projeto por rolos de no máximo $100 \mathrm{~mm}$ de diâmetro permitiu o desenvolvimento de uma máquina compacta capaz de processar bambus de médios diâmetros como previsto. Porém, houve a necessidade de inicialmente abrir os colmos ao meio e em alguns casos remover previamente os diafragmas. Rolos maiores 
devem ampliar o diâmetro de processo e provavelmente eliminar a exigência de retirada prévia dos diafragmas, bem como em alguns casos até eliminar a necessidade de abrir o colmo ao meio.

Figura 12-Diferentes tipos de sulcos decorrentes da geometria e ajuste dos rolos

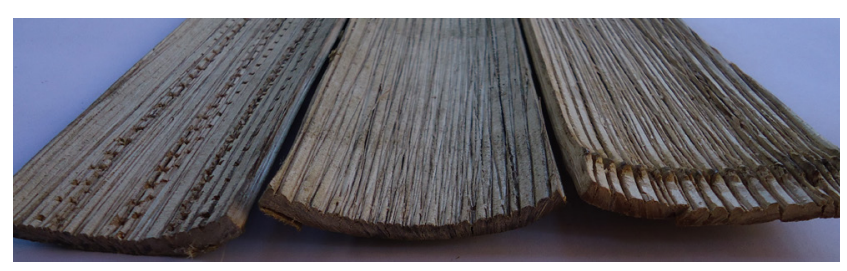

Fonte: Autoria própria

A figura 13 apresenta um colmo de bambu espécie Phyllostachys aurea (Áurea) e suas distintas fases de planificação. Inicialmente o colmo foi dividido ao meio, retirado o diafragma e na sequência foi passado varias vezes pela combinação de rolos apresentados na parte inferior da figura 11. Em cada passagem foi conformado uma parte do colmo com aproximadamente $10 \mathrm{~mm}$ de largura, sendo após varias passagens obtido o produto planificado mostrado á direita desta.

Ainda, analisando e comparando as dimensões do colmo desta figura 13 que possuía diâmetro médio de $45 \mathrm{~mm}$; logo um perímetro $138 \mathrm{~mm}$; com a largura de $71 \mathrm{~mm}$ do produto resultante da planificação da metade deste colmo, verifica-se que para um mesmo comprimento a área externa deste e do produto final são aproximadamente a mesma.

Figura 13- Phyllostachys aurea planificado. Colmo, meio colmo e produto final.

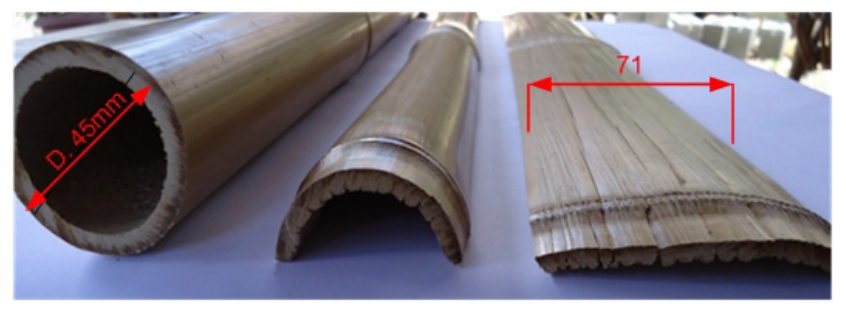

Fonte: Autoria própria

Por esta razão, mesmo sem quantificar, depois de retira dos os diafragmas, material interno sem valor e ainda possível esquadrejamento deduz-se que este processo é eficiente se comparando os valores de produto final verso inicial apresentados na literatura para outros processos como torneamento ou serramento. Um futuro estudo estatístico pode vir a determinar o percentual real de rendimento volumétrico do processo em estudo.

O produto plano obtido a partir do Phyllostachys aurea e apresentado na figura 13 valida o modelo conceitual idealizado anteriormente para o equipamento e processo. O Bambusatuldoides também apresentou excelentes resultados, já a planificação do Phyllostachys pubescens merece mais estudos de perfis de rolos e processo para se obter resultados similares aos outros.

A partir dos produtos planificados foram confeccionadas diversas amostras de placas/painéis compostos usando somente os recursos para trabalhar madeiras disponíveis na marcenaria escola, comprovando que um dos gargalos para industrialização é o processamento primário.

A figura 14 apresenta da parte superior para baixo todas as etapas de fabricação uma peça composta de bambu Phyllostachys pubescens (Mossô), fibra de coco, serragem, adesivo e lâmina de bambu de $1 \mathrm{~mm}$ de espessura obtida por torneamento. Após a prensagem com cola a base de PVA esta peça foi plainada em uma das faces e esquadrejada apresentando ao final bom aspecto visual e estrutural.

Figura 14-Phyllostachspubescens em diversas fases do processo. a) Colmo planificado, b) prensado frente, c) prensado verso, d) painel plainado
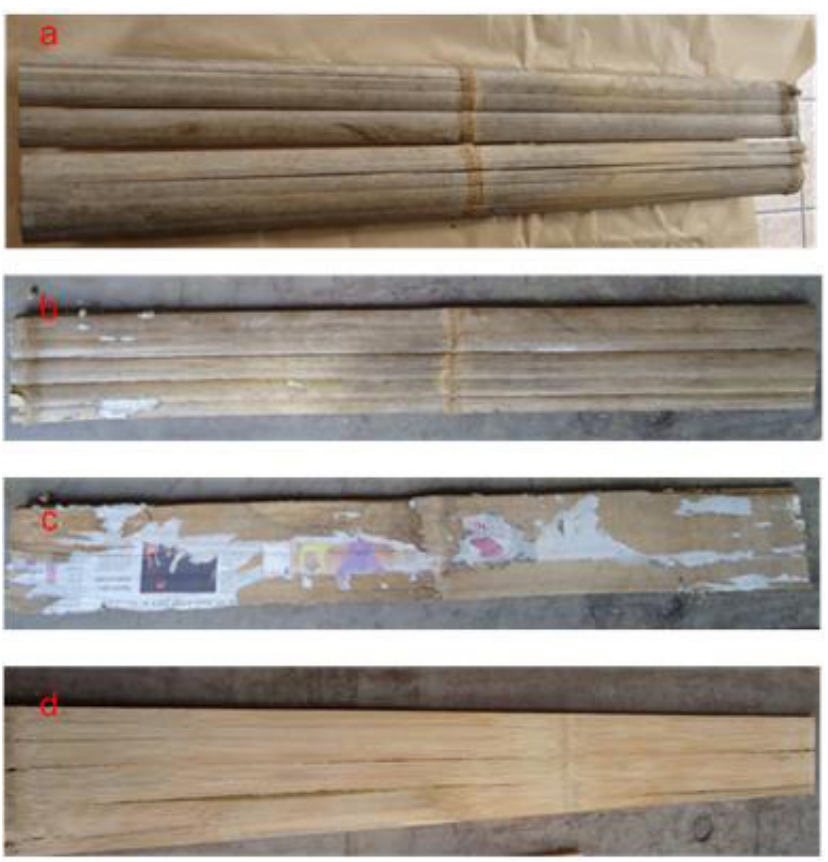

Fonte: Autoria própria

As fissuras longitudinais, que neste caso devem ser corrigidas para se obter uma peça com fino acabamento, denotam a necessidade de desenvolver prensas e processo com controle preciso de força em dois sentidos para a colagem de forma mais eficiente. Os grampos sargentos e artifícios utilizados não foram eficientes, neste caso, em relação a este problema.

Na figura 15 é apresentado um painel composto por bambu Bambusatuldoides (Tuldoide) nas duas faces, com 
as fibras alinhadas em um único sentido preenchido com fibra seca de coco para reforço transversal. Esta composição simples quando flexionada manualmente apresentou boa resistência no sentido longitudinal e transversal devido às fibras de coco.

Figura 15 - Placa planificada prensada de bambu tuldoide com duas camadas interposta com fibra, vista superior e de topo.

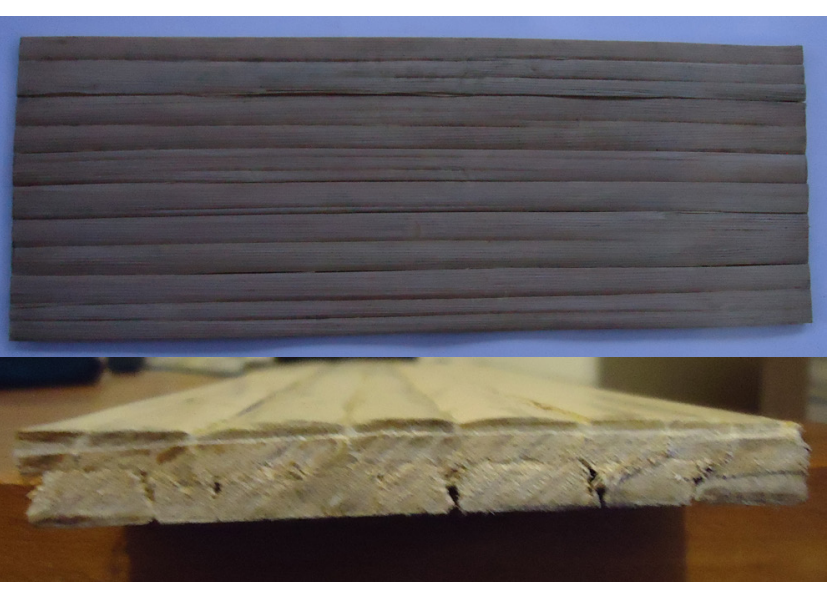

Fonte: Autoria própria

Em uma análise visual e tátil as amostras de painel obtidas vistas na figuras 14 e figura 15, apresentaram razoável planicidade, aparente resistência, bom acabamento bem como agradável aspecto e com boas possibilidade de compor com as madeiras para fabricação de móveis. A amostra da figura 15 chamou a atenção pela possibilidade de agregação de valor através de industrialização de produtos derivados de bambus de espécie nativa colhidos nas proximidades da marcenaria e até então considerados sem valor.

Apesar dos resultados iniciais satisfatórios, para validação de aplicações segmentadas dos painéis, existe a necessidade de produção de maiores quantidades avaliando parâmetros ora não analisados pela limitação dos equipamentos e instrumentos existentes na marcenaria/ escola utilizada e pelos objetivos deste projeto.

Do conhecimento adquirido de outros experimentos para de obtenção de ripas e lâminas por serra e torneamento, observa-se que este processo em estudo necessariamente não é concorrente daqueles, e sim complementar, pois varas de pequeno diâmetro ou as pontas de varas dos bambus de grande diâmetro, são inviáveis ou difíceis de serem processadas pelas técnicas citadas e fáceis por esta.

A partir dos colmos planificados os equipamentos usuais da marcenaria permitiram a fabricação de produtos que podem compor em partes ou totalmente os moves fabricados. Equipamentos simples para viabilizar processos primários eficientes e de fácil aplicação para planificar um colmo podem colaborar com novas possibilidades de industrialização de bambus permitindo agregar valor a esta matéria prima, através de produtos mais elaborados.

Finaliza-se com agradecimentos ao Fundamas Centro XV e ao instrutor Mario Jorge de Oliveira pela disponibilização dos ambientes e colaboração com este projeto, bem como na expectativa de que na continuidade se faça uso do bambu processado nas atividades da referida marcenaria escola.

\section{REFERÊNCIAS}

CZIULIK, C. Development of a Computer Evaluation Model for Assessing Mechanical Systems Conceptual Design Alternatives. University of Surrey, SURREY, Inglaterra.1998.

FRDI; Bamboo veneering machine fabricated. Products Research and Development Institute (FPRDI)Department of Science and Technology (DOST). www. frdi.org. Acesso em julho de 2008.

HIDALGO, L.O.; Bambu - su cultivo y aplicaciones em: fabricación de papel, construcción, Arquitectura, Ingeniería, Artesanía. EstudiosTecnicos Colombianos Ltda., Colombia, 318p, 1974.

LERIPIO, A. A.; LERIPIO, D.C.; Cadeias produtivas sustentáveis. UFSC- Mix Sustentável, V.1 n.1/2015

MARINHO, N. P.; Análise da Viabilidade de Produção de Móveis com Painéis e/ou Chapas Laminadas de Bambu Visando a geração de Trabalho e Renda. Curitiba, PR. Trabalho de Diplomação. Curso Superior de Tecnologia em Móveis do Departamento Acadêmico de Desenho Industrial da Universidade Tecnológica Federal do Paraná-2007.

MARINHO, N. P.; CASAGRANDE, E. F. J.; SALAMON, C.; Revisão de Métodos para Obtenção de Laminas para Fabricação de Painéis Laminados de Bambu com Baixa mecanização. Relatório PIBIC-CNPq. Departamento de Engenharia de Construção Civil, Universidade Tecnológica Federal do Paraná - UTFPR - Unidade Curitiba - 2007

OSHIMA, B.; SETSUO F.; OLIVEIRA SILVA, S.; Projeto mecânico e implementação de protótipo de serra CNC para bambu. Trabalho de Conclusão de Curso do Curso 
requisito parcial a obtenção do grau de Tecnologia Mecânica Modalidade Mecatrônica da Universidade Tecnológica Federal do Paraná unidade Curitiba. Curitiba 2011.

OSTAPIV, F.; Resistência mecânica do material compósito: madeira de eucalipto-lâmina de bambu. 2011. 148 f. Tese (Doutorado em Engenharia Mecânica) Faculdade de Engenharia do Campus de Guaratinguetá, Universidade Estadual Paulista, Guaratinguetá, 2011.

PAHL, G.; BEITZ, W; FELDHUSEN J.; GROTE K.H.; Engineering Design: A Systematic Approach, Third Edition Translators and Editors: Ken Wallace and Luciënne T. M. Blessing Springer-Verlag-London, 2007.

SALAMON. C.; Ensaios para viabilizar a laminação do bambu Dendrocalamus giganteus em operações de torneamento sem centros. 2009. $113 \mathrm{f}$. Tese (Doutorado em Engenharia Mecânica) - Faculdade de Engenharia do Campus de Guaratinguetá Universidade Estadual Paulista, Guaratinguetá, 2009. 